\title{
Statistical Investigation of Production Performance of Cumin in India
}

\author{
P. Mishra ${ }^{16}$, K. Padmanaban ${ }^{2}$, B.S. Dhekale ${ }^{3}$ and A.K. Tailor ${ }^{4}$ \\ ${ }^{1}$ College of Agriculture, Jawaharlal Nehru Krishi Vishwa Vidyalaya, Powarkheda, Madhya Pradesh, India \\ ${ }^{2}$ Department of Agricultural Statistics, Bidhan Chandra Krishi Viswavidyalaya, Mohanpur, Nadia, West Bengal, India \\ ${ }^{3}$ Sher-e-Kashmir University of Agriculture Sciences and Technology, Kashmir, J\&K, India \\ ${ }^{4}$ Department of Statistics, National Horticultural Research and Development Foundation, Regional Research Station, Nashik, \\ Maharashtra, India
}

*Corresponding author: pradeepjnkvv@gmail.com

\begin{abstract}
Cumin is the dried, white fruit with greyish brown colour of a small slender annual herb. The surface of the fruit has 5 primary ridges, alternatively has 4 less distinct secondary ridges bearing numerous short hairs. The flowers are white or rose-colored in small umbels. By and large there has been considerable expansion in area and production of cumin in Gujarat, Rajasthan and whole India. Considering the productivity of cumin except Gujarat remaining state Rajasthan and whole India registered the negative growth rate. Moreover, in states and whole India different factors are influencing productivity of cumin; by and large nitrogen is the major factor to significantly effect on the cumin productivity. Also forecasting has been done using comparing ARIMA and GARCH model for year 2020. Globally seeing the cumin seed demand this forecasting can be used policy implications and future trend of production and productivity of cumin in India and major states. This helps shows that cumin production reached 375 and 562 ‘ 000 tonnes in year 2020 for Gujarat and whole India respectively.
\end{abstract}

Keywords: Trend analysis, factor of production, ARIMA, GARCH, forecasting

The major countries that produce jeera or cumin seeds are India, Turkey, Syria, Iran and China. India is the biggest producer of Cumin Seeds in global spice market and new crop of Indian Cumin Seeds start every year February, this year crop expected 3.30 thousand metric tons out of this more than $70 \%$ of the crop consumed by domestic \& Globally exported, since next new crop - 2017 have to go long path of 8 months and this year price are already high than comparing to previous years (Spices board of India, 2017). Syria stands second in the list with a production figure of 25000 tons. This clears out the India is far more dominant in this context than any other country as it also possess the maximum area in the cultivation of the spice. Turkey and Iran have the same level of production i.e. 15000 to 20000 tons of cumin seeds and that makes them both stand third in the leading producer's list.
Though Syria, Turkey and Iran have a much lesser level of production as compared to India but these countries have an equally significant influence in the determination of world jeera prices. In India, the level of production and the total area under jeera cultivation has increased significantly during the last few years. Rajasthan is largest jeera producing state in the country. It contributed around 1.2 lakh tons in the country's total produce in the year 200304 and it also have the maximum area under jeera cultivation i.e. around 2.25 lakh hectares. Gujarat is the second largest cumin seed producer in India. Rajasthan and Gujarat contribute to approximately 90 per cent of the production in the India (CRN report, 2016). Cumin seeds contain numerous phyto-chemicals that are known to have antioxidant, carminative and anti-flatulent properties. The seeds are an excellent source of dietary fiber and also 
contain certain health-benefiting essential oils such as cuminaldehyde. The active principles in the cumin may improve gut motility and help in digestion by augmenting gastro-intestinal enzyme secretions. The spice is an excellent source of minerals like iron, copper, calcium, potassium, manganese, selenium, zinc and magnesium. It also contains very good amounts of B-complex vitamins such as thiamine, vitamin B-6, niacin, riboflavin, and other vital antioxidant vitamins like vitamin $\mathrm{E}$, vitamin $\mathrm{A}$, and vitamin C. Mishra et al. (2017) studied the future trend of black pepper in India. Sahu and Mishra (2017) forecasted for total species for India and China using ARIMA model. In present Investigation the factors like fertilizers, environmental factors etc. affecting the production of cumin in India and its future performance using forecasting models.

\section{MATERIALS AND METHODS}

India is the largest producer and consumer of cumin in the world. Indian output is currently estimated to be around 445 thousand tonnes in the year of 2014 . Gujarat and Rajasthan are the major production centers of cumin in the country contributing 99 percentage of total production. For our study data of cumin area, production and productivity from 1991-2000 to 2013-14 were collected and analysed.

\section{Descriptive statistics}

Descriptive statistics are used to summarize and describe data. Some measures that are commonly used to describe a data set are measures of central tendency and measures of variability or dispersion and measures of association. Measures of central tendency include the mean, median and mode, while measures of variability include the standard deviation (or variance), range, the minimum and maximum values of the variables, kurtosis, skewness, simple growth rate and compound growth rate.

\section{Trend models}

Trend models generally pictures the overall movement of any time series. For this study parametric models were explored to trace the trends of the production and trade behaviour (Borthakur and Bhattacharya, 1998) of cumin in India. The best fit models which are chosen for estimating the growth pattern is based on the $\mathrm{R}^{2}$ values obtained.
The model with highest $\mathrm{R}^{2}$ value is considered as the best model.

\section{Regression analysis}

For the purpose of present study, the following regression model will be assumed.

$$
Y=f\left(R F, T_{\max }, T_{\min }, N, P, K\right)
$$

where,

$$
\begin{aligned}
& \mathrm{Y}=\text { Cumin productivity }(\mathrm{kg} \text { per hectare) } \\
& \mathrm{RF}=\text { Rainfall }(\mathrm{mm}) \\
& \mathrm{T}_{\text {max }}=\text { Mean maximum temperature }\left({ }^{\circ} \mathrm{C}\right) \\
& \mathrm{T}_{\min }=\text { Mean minimum temperature }\left({ }^{\circ} \mathrm{C}\right) \\
& \mathrm{N}=\text { Total nitrogen fertilizer consumption } \\
& \mathrm{P}=\text { Total phosphorous fertilizer consumption } \\
& \mathrm{K}=\text { Total potash fertilizer consumption }
\end{aligned}
$$

\section{Autoregressive Integrated Moving Average (ARIMA) Model}

The ARIMA methodology is also called as BoxJenkins methodology. The emphasis of these methods is not on constructing single equation or simultaneous equation models but on analyzing the probabilistic or stochastic properties of economic time series on their own under the philosophy let the data speak for themselves and allow $Y_{t}$ to be explained by past or lagged values of $\mathrm{Y}$ itself and stochastic error terms.

\section{The Box-Jenkins methodology}

Box-Jenkins methodology helps to find the values of $\mathrm{p}, \mathrm{d}$ and $\mathrm{q}$ of an ARIMA model for a time series.

\section{Autoregressive model}

The notation AR $(p)$ refers to the autoregressive model of order $p$. The $\operatorname{AR}(p)$ model is written:

$$
X_{t}=c+\sum_{i=1}^{P} \rho_{i} X_{t}+\varepsilon_{t}
$$

where, $\rho_{1^{\prime}} \rho_{2^{\prime}} \ldots \ldots \rho_{p}$ are the parameters of the model, $c$ is a constant and $\varepsilon_{t}$ is white noise. Sometimes the constant term is avoided.

\section{Moving Average model}

The notation MA $(q)$ refers to the moving average series of order $q$ : 


$$
X_{t}=\mu+\varepsilon_{t}+\sum_{i=1}^{q} \theta_{i} \varepsilon_{t-i}
$$

Where the $\theta_{1}, \ldots, \theta_{q}$ are the parameters of the model, $\mu$ is the expectation of $X_{t}$ (often assumed to equal $0)$, and the $\varepsilon_{t^{\prime}} \varepsilon_{t-1} \ldots$

\section{GARCH (Generalized Autoregressive Conditional Heteroskedasticity)}

Bollerslev (1986) proposed the Generalized Auto Regressive Conditional Heteroscedascity (GARCH) model in which conditional variance is also a linear function of its own lags and has the following form:

$$
\begin{gathered}
\mathrm{h}_{\mathrm{t}}=\alpha_{0}+\alpha_{1} \varepsilon_{\mathrm{t}-1}^{2}+\ldots+\alpha_{\mathrm{q}} \varepsilon_{\mathrm{t}-\mathrm{q}}^{2}+\beta_{1} \mathrm{~h}_{\mathrm{t}-1}+\ldots+\beta_{\mathrm{p}} \mathrm{h}_{\mathrm{t}-\mathrm{p}} \\
h_{t}=a_{0}+\sum_{i=1}^{q} a_{i} \varepsilon_{t-i}^{2}+\sum_{j=1}^{p} b_{j} h_{t-j}
\end{gathered}
$$

A sufficient condition for the conditional variance to be positive is,

$$
a_{0}>0, a_{i} \geq o, i=1,2, \ldots, q ; b_{j} \geq 0, j=1,2, \ldots, p
$$

The GARCH (p, q) process is weakly stationary if and only if $\sum_{i=1}^{q} a_{i}+\sum_{j=1}^{p} b_{j}<1$. The most popular GARCH model in applications is the $\operatorname{GARCH}(1,1)$

model. The express GARCH model in terms of ARMA model, denote $\eta_{t}=\varepsilon_{t}^{2}-h_{t}$. Then from eq. (1).

$\varepsilon_{t}^{2}=a_{0}+\sum_{i=1}^{\operatorname{Max}(p, q)}\left(a_{i}+b_{j}\right) \varepsilon_{t-i}^{2}+\eta_{t}+\sum_{j=1}^{p} b_{j} \eta_{t-j}$

Thus, a GARCH model can be regarded as an extension of the ARMA approach to squared series $\left\{\varepsilon_{t}^{2}\right\}$.

\section{RESULTS AND DISCUSSION}

\section{Per se performance of cumin production in India}

Per se performance of cumin is presented in Table 1. From the table, one can find that in India, the area of cumin cultivation increased from 73.60 thousand hectares (1991) to 858.90 thousand hectares (2014) with an average area of 321.88 thousand hectares with registered simple growth rate of India is $\mathbf{1 4 . 9 6}$ over the study period. Leptokurtic and positively skewed nature of Gujarat, Rajasthan and whole India indicates that the steady improvement in area during the early period under consideration and remain almost same in later half. Considering the states, Gujarat regarded highest average area (236.28 thousand hectares) of cumin followed by Rajasthan (221.83 thousand hectares) with registered simple growth rate of 4.25 percent for Gujarat and 4.80 percent for Rajasthan.

Cumin production in India has increased from 28.20 thousand tonnes (1991) to 513.90 thousand tonnes (2014) during the study period and has registered a simple growth rate of 41.90 percent per annum. In case of Gujarat production has increased from 28.80 thousand tonnes to 283 thousand tonnes and registered growth rate of 23.74 percent. Considering Rajasthan, the production has increased from 23.67 thousand tonnes to 178 thousand tonnes and with simple growth rate of 18.77 percent. Both states and whole India, positive skewness and kurtosis indicates that the maximum growth has taken place during the early period under study and remained almost same in the latter half. In India, cumin with an average productivity of 413.34 $\mathrm{kg} / \mathrm{ha}$ and productivity varied from $330 \mathrm{~kg}$ per hectare (1991) to $498.67 \mathrm{~kg}$ per hectare (2014) with the registered simple growth rate of -0.01 percent. Gujarat (an average productivity of $469.36 \mathrm{~kg} / \mathrm{ha}$ and productivity varied from $303.01 \mathrm{~kg}$ per hectare to $589.64 \mathrm{~kg}$ per hectare) is the best state followed by Rajasthan (an average productivity of $351.76 \mathrm{~kg}$ / ha and productivity varied from 219.42 to 531.02 $\mathrm{kg} / \mathrm{ha}$ ) with simple growth rate of 3.58 percent (Gujarat) and -1.34 percent (Rajasthan) respectively. In Gujarat, the negative value of kurtosis (-1.34) and skewness (-0.34) indicates that there has been marginal shift of productivity under cumin during recent year under study. Both Rajasthan and whole India, platykurtic and negative skewness (-0.01) reveals that steady improvement in productivity during the early period under study and remain almost same in later half.

From the table it is clear that Gujarat is the single largest producer of cumin in the country accounting for 60 per cent of total production and the rest of the output comes from Rajasthan. Gujarat and Rajasthan together account for about 99 per cent 
Table 1: Per se performance of cumin production in major states of India during 1991- 2014

\begin{tabular}{cccccccccc}
\hline & \multicolumn{3}{c}{ Area ('000 ha) } & \multicolumn{3}{c}{ Production (‘000 t) } & \multicolumn{3}{c}{ Productivity (kg/ha) } \\
\cline { 2 - 10 } & Gujarat & Rajasthan & India & Gujarat & Rajasthan & India & Gujarat & Rajasthan & India \\
\hline Mean & 236.28 & 221.83 & 321.88 & 110.25 & 75.87 & 182.28 & 469.36 & 351.76 & 413.34 \\
SE & 12.87 & 14.19 & 33.92 & 16.72 & 8.92 & 25.98 & 19.04 & 16.13 & 7.19 \\
Kurtosis & 0.78 & -0.84 & -0.03 & 0.27 & 0.11 & -0.30 & -1.34 & -0.24 & -0.52 \\
Skewness & 1.14 & 0.58 & 0.82 & 1.19 & 1.00 & 1.13 & -0.34 & 0.44 & 0.19 \\
Minimum & 149.60 & 135.11 & 73.60 & 28.80 & 23.67 & 28.20 & 303.01 & 219.42 & 330.00 \\
Maximum & 374.00 & 368.00 & 858.90 & 283.00 & 178.00 & 513.90 & 589.64 & 531.02 & 498.67 \\
SGR \% & 4.25 & 4.80 & 14.96 & 23.74 & 18.77 & 41.90 & 3.58 & -1.34 & -0.01 \\
CGR \% & 2.97 & 3.25 & 6.05 & 8.25 & 7.36 & 7.59 & 2.62 & -1.61 & -0.01 \\
\hline
\end{tabular}

Table 2: Trends in area, production and productivity of cumin in major states of India

\begin{tabular}{|c|c|c|c|c|c|c|c|c|c|c|}
\hline \multirow[b]{3}{*}{ States } & \multirow{3}{*}{ Equation } & \multicolumn{8}{|c|}{ Area ('000 ha) } & \\
\hline & & \multicolumn{4}{|c|}{ Model Summary } & \multicolumn{5}{|c|}{ Parameter Estimates } \\
\hline & & $\mathbf{R}^{2}$ & $\mathbf{F}$ & df1 & $\mathrm{df} 2$ & Sig. & Const. & b1 & b2 & b3 \\
\hline Gujarat & Quadratic & 0.91 & 52.29 & 2 & 21 & 0.00 & 201 & $-5.81^{*}(3.31)$ & $0.530^{* *}(0.12)$ & \\
\hline Rajasthan & Cubic & 0.59 & 3.47 & 3 & 20 & 0.03 & 104 & $49.41^{*}(19.75)$ & $-5.04^{*}(1.81)$ & $0.140^{* *}(0.04)$ \\
\hline India & Linear & 0.66 & 17.48 & 1 & 22 & 0.00 & 77 & $8.44^{* *}(2.02)$ & & \\
\hline \multicolumn{11}{|c|}{ Production ('000 tonnes) } \\
\hline \multirow[b]{2}{*}{ States } & \multirow{2}{*}{ Equation } & \multicolumn{4}{|c|}{ Model Summary } & \multicolumn{5}{|c|}{ Parameter Estimates } \\
\hline & & $\mathbf{R}^{2}$ & $\mathbf{F}$ & df1 & $\mathrm{df2}$ & Sig. & Const. & b1 & b2 & b3 \\
\hline Gujarat & Quadratic & 0.96 & 163.44 & 2 & 21 & 0.00 & 66 & $-8.97^{* *}(2.59)$ & $0.766^{* *}(0.10)$ & \\
\hline Rajasthan & Cubic & 0.63 & 4.40 & 3 & 20 & 0.01 & 11 & $21.79^{*}(11.88)$ & $-2.220^{* *}(1.09)$ & $0.06^{*}(0.02)$ \\
\hline India & Linear & 0.57 & 10.55 & 1 & 22 & 0.04 & 44 & $2.83^{* *}(0.873)$ & & \\
\hline \multicolumn{11}{|c|}{ Productivity (kg/ha) } \\
\hline \multirow{2}{*}{ States } & \multirow{2}{*}{ Equation } & \multicolumn{4}{|c|}{ Model Summary } & \multicolumn{5}{|c|}{ Parameter Estimates } \\
\hline & & $\mathbf{R}^{2}$ & $F$ & df1 & df2 & Sig. & Const. & b1 & b2 & b3 \\
\hline Gujarat & Linear & 0.79 & 36.89 & 1 & 22 & 0.00 & 339 & $10.45^{* *}(1.72)$ & & \\
\hline Rajasthan & Linear & 0.52 & 8.05 & 1 & 22 & 0.01 & 424 & $-6.46^{*}(2.28)$ & & \\
\hline India & Linear & 0.68 & 32.37 & 1 & 37 & 0.00 & 331 & $2.98^{* *}(0.52)$ & & \\
\hline
\end{tabular}

Note: ** significant at 1\%; * significant at 5\%; figures in the parenthesis indicates Standard Error; df1: Regression degrees of freedom; df2: Residual degrees of freedom.

of cumin production in the country. Both Gujarat and Rajasthan used to produce almost equal amount output until the early 2000s. But output from Gujarat increased rather steeply from year 2001 onwards and became the single largest producer. Though, Negative growth rate of cumin productivity in Rajasthan is the reason behind it's number two position in the cumin production. Unseasonal rainfall at the time flowering is likely to affects the productivity of Rajasthan. Research on development of off season cumin varieties may sustain the productivity of cumin in Rajasthan.

\section{Trend analysis of area, production and productivity of cumin}

Knowing the above overall performance, path of movement of the series was traced through parametric trends models. To workout the trends in area, production and yield of cumin different parametric model like polynomial, logarithmic, compound, growth, and exponential models as discussed in material and method section are attempted too. Among the competitive models the best model is selected on the basis of the maximum $R^{2}$ value, significance of the model and 
its coefficients. The following section presents the results of this exercise (Table 2).

In all data series of area, production and productivity of cumin in major states and whole India, non-linear patterns are revealed (Fig. 1.A, B and C) that, area and production series of Gujarat and Rajasthan fitted well with quadratic model and cubic model respectively. Productivity of both states and all data series of whole India follow the linear trend. Positive nature of third coefficient indicates increasing in recent past in area and production of cumin in Rajasthan. Linear trend in productivity indicates that there is no change in productivity of cumin over the study period.

Thus from the test of trend analysis of area, production and productivity of cumin in major states of India the following important features has emerges out. All data series of cumin production follows the definite pattern of trend. Rajasthan shows increasing trend in area and production series. Trend in area and production of cumin in Gujarat and Rajasthan shows the increased in nature, visualized by positive b2 coefficient in Gujarat and b3 coefficient in Rajasthan. The increased trend shows interest of farmers to grow cumin; whereas productivity of cumin fitted with linear trend, almost straight line in entire study period. So meet the global need necessary actions are required to increase the production of cumin.

\section{Regression analysis of factor affecting the productivity of cumin in major states of India}

In order to find out the relationship of productivity with climatological and nutrients factors multiple linear regression equations are fitted. The most important factors influencing cumin productivity in major states is identified by using step-down regression analysis (Table 3). A significant coefficient of nitrogen factor on productivity of cumin noticed in Gujarat and Rajasthan. A unit change in nitrogen fertilizer would lead to an increase in productivity of cumin by $0.27 \mathrm{~kg}$ per hectare in Gujarat and decrease in productivity by $0.204 \mathrm{~kg}$ per hectare in Rajasthan respectively. Similarly, in whole India potassium fertilizer and $\mathrm{T}_{\min }$ had significant coefficient on cumin productivity. Thus, one unit change in potassium fertilizer and $\mathrm{T}_{\min }$ would lead to increase in productivity of cumin by $0.016 \mathrm{~kg}$ per hectare and $29.205 \mathrm{~kg}$ per hectare respectively. From the above table it is clearly visible that not all factors are equally effective on productivity of cumin. Moreover, in states and whole India different

Table 3: Regression analysis of factor affecting the productivity of cumin in major states of India

\begin{tabular}{|c|c|c|c|c|c|c|}
\hline \multicolumn{7}{|c|}{ Gujarat } \\
\hline Model & & B & SE & Sig. & $\mathbf{R}^{2}$ & Adj. $R^{2}$ \\
\hline \multirow[t]{7}{*}{$\mathrm{A}$} & (Constant) & 106.257 & 1535.453 & 0.946 & \multirow{7}{*}{0.62} & \multirow{7}{*}{0.48} \\
\hline & $\mathrm{N}$ & 0.447 & 0.202 & 0.041 & & \\
\hline & $\mathrm{P}$ & -1.533 & 0.916 & 0.112 & & \\
\hline & K & 2.462 & 1.53 & 0.126 & & \\
\hline & RF & 0.036 & 0.063 & 0.572 & & \\
\hline & $\mathrm{T}_{\max }$ & -13.981 & 40.267 & 0.733 & & \\
\hline & $\mathrm{T}_{\min }$ & 34.316 & 43.218 & 0.438 & & \\
\hline \multirow[t]{2}{*}{ B } & (Constant) & 280.125 & 39.224 & 0.000 & \multirow{2}{*}{0.54} & \multirow{2}{*}{0.52} \\
\hline & $\mathrm{N}$ & 0.27 & 0.053 & 0.000 & & \\
\hline \multicolumn{7}{|c|}{ Rajasthan } \\
\hline Model & & B & SE & Sig. & $\mathbf{R}^{2}$ & Adj. $R^{2}$ \\
\hline \multirow[t]{7}{*}{ A } & (Constant) & -1810.24 & 5224.427 & 0.733 & \multirow{7}{*}{0.523} & \multirow{7}{*}{0.484} \\
\hline & $\mathrm{N}$ & -0.178 & 0.242 & 0.472 & & \\
\hline & $\mathrm{P}$ & -0.067 & 0.492 & 0.893 & & \\
\hline & K & 0.055 & 0.959 & 0.955 & & \\
\hline & RF & -0.081 & 0.16 & 0.618 & & \\
\hline & $\mathrm{T}_{\max }$ & 187.905 & 401.57 & 0.646 & & \\
\hline & $\mathrm{T}_{\min }^{\max }$ & -202.172 & 422.719 & 0.639 & & \\
\hline \multirow[t]{2}{*}{ B } & (Constant) & 454.97 & 38.61 & 0.000 & \multirow{2}{*}{0.473} & \multirow{2}{*}{0.424} \\
\hline & $\mathrm{N}$ & -0.204 & 0.071 & 0.009 & & \\
\hline
\end{tabular}




\begin{tabular}{|c|c|c|c|c|c|c|}
\hline \multicolumn{7}{|c|}{ India } \\
\hline Model & & B & SE & Sig. & $\mathbf{R}^{2}$ & Adj. $R^{2}$ \\
\hline \multirow[t]{7}{*}{ A } & (Constant) & 299.318 & 437.853 & 0.498 & & \\
\hline & $\mathrm{N}$ & 0.007 & 0.007 & 0.325 & & \\
\hline & $\mathrm{P}$ & -0.048 & 0.024 & 0.053 & & \\
\hline & K & 0.084 & 0.034 & 0.019 & 0.697 & 0.586 \\
\hline & $\mathrm{RF}$ & 0.092 & 0.065 & 0.164 & & \\
\hline & $\mathrm{T}_{\max }$ & -39.895 & 25.443 & 0.125 & & \\
\hline & $\mathrm{T}_{\min }$ & 73.79 & 30.939 & 0.022 & & \\
\hline \multirow[t]{3}{*}{ B } & (Constant) & -109.571 & 267.617 & 0.684 & & \\
\hline & K & 0.016 & 0.007 & 0.027 & 0.593 & 0.554 \\
\hline & $\mathrm{T}_{\min }$ & 29.205 & 15.69 & 0.070 & & \\
\hline
\end{tabular}

Note: $A$ is full model; $B$ is step-down regression model.
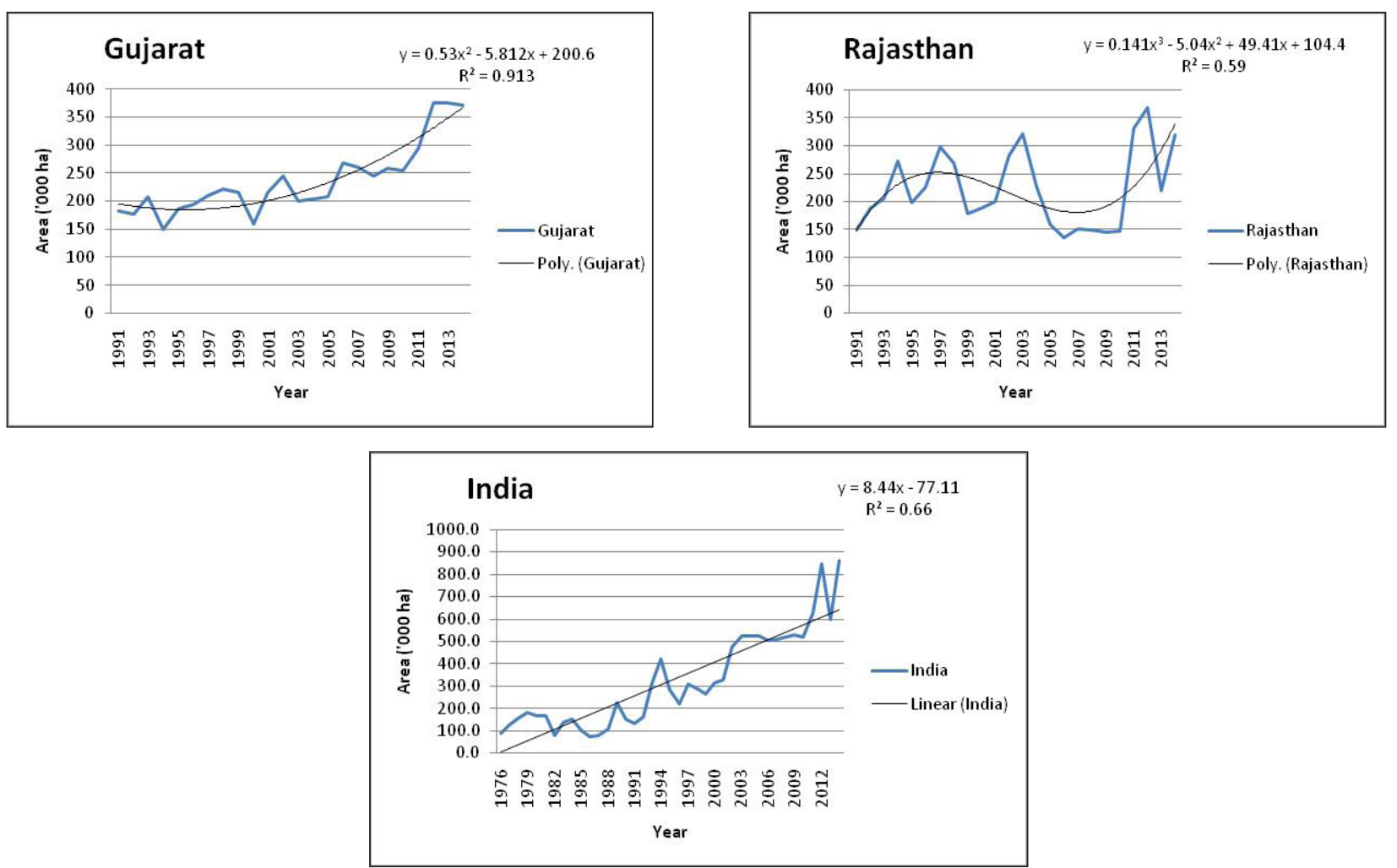

Fig. 1A: Observed and expected trends of area under cumin in major states of India
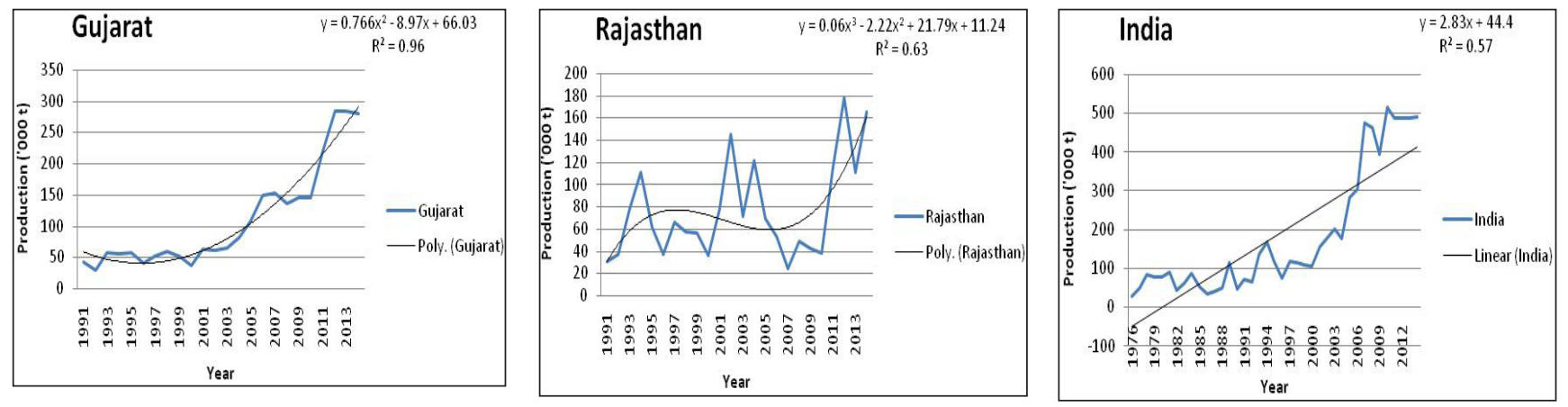

Fig. 1B: Observed and expected trends of production under cumin in major states of India 
Table 4: Best fitted ARIMA and GARCH models for area under cumin in India

\begin{tabular}{|c|c|c|c|c|c|c|c|c|c|c|}
\hline \multirow{2}{*}{ State } & \multirow{2}{*}{ Model } & \multicolumn{9}{|c|}{ Model Selection Criteria } \\
\hline & & AIC & BIC & ME & RMSE & MAE & MPE & MAPE & MASE & $\mathbf{R}^{2}$ \\
\hline \multicolumn{11}{|c|}{ Area $(000 ' h a)$} \\
\hline Gujarat & $\operatorname{ARIMA}(1,2,1)^{*}$ & 212.51 & 213.55 & 8.69 & 35.51 & 26.69 & 1.91 & 12.24 & 0.95 & 0.51 \\
\hline & No GARCH & & & & & & & & & \\
\hline \multirow[t]{2}{*}{ Rajasthan } & $\operatorname{ARIMA}(1,1,2)^{*}$ & 244.08 & 247.36 & 1.51 & 53.34 & 44.96 & -5.58 & 21.42 & 0.95 & 0.58 \\
\hline & GARCH $(1,2)$ & 278.95 & 287.19 & 2.44 & 57.36 & 52.17 & -3.53 & 24.21 & 1.75 & 0.52 \\
\hline \multirow[t]{2}{*}{ India } & $\operatorname{ARIMA}(1,1,2)^{*}$ & 445.83 & 453.74 & 0.35 & 20.72 & 19.42 & -11.71 & 5.42 & 0.96 & 0.85 \\
\hline & No GARCH & & & & & & & & & \\
\hline \multicolumn{11}{|c|}{ Production ('000 tonnes) } \\
\hline \multirow[t]{2}{*}{ Gujarat } & $\operatorname{ARIMA}(1,1,1)^{*}$ & 197.81 & 199.00 & 0.00 & 23.86 & 18.11 & -11.39 & 24.59 & 0.97 & 0.88 \\
\hline & No GARCH & & & & & & & & & \\
\hline \multirow[t]{2}{*}{ Rajasthan } & $\operatorname{ARIMA}(1,1,2)^{*}$ & 226.16 & 230.10 & 0.45 & 36.43 & 30.27 & -26.00 & 50.78 & 0.88 & 0.61 \\
\hline & GARCH $(1,2)$ & 254.24 & 262.49 & 0.78 & 39.25 & 31.40 & -19.49 & 50.78 & 1.23 & 0.49 \\
\hline \multirow[t]{2}{*}{ India } & $\operatorname{ARIMA}(1,2,1)^{*}$ & 405.62 & 408.89 & 0.00 & 47.11 & 33.38 & -11.62 & 29.15 & 0.99 & 0.91 \\
\hline & No GARCH & & & & & & & & & \\
\hline \multicolumn{11}{|c|}{ Productivity $(\mathrm{Kg} / \mathrm{Ha})$} \\
\hline \multirow[t]{2}{*}{ Gujarat } & ARIMA $(1,1,1)$ & 243.50 & 244.55 & 11.92 & 74.28 & 52.56 & 1.29 & 12.15 & 0.95 & 0.58 \\
\hline & GARCH $(1)^{*}$ & 239.43 & 241.32 & 9.88 & 71.24 & 41.41 & 0.99 & 10.31 & 0.79 & 0.57 \\
\hline \multirow[t]{2}{*}{ Rajasthan } & $\operatorname{ARIMA}(0,2,1)^{*}$ & 251.91 & 253.05 & -5.48 & 54.20 & 40.60 & -2.83 & 12.02 & 0.96 & 0.68 \\
\hline & GARCH (1) & 279.32 & 285.21 & -4.87 & 57.74 & 56.01 & -1.00 & 17.62 & 1.57 & 0.53 \\
\hline \multirow[t]{2}{*}{ India } & $\operatorname{ARIMA}(2,1,1)^{*}$ & 375.66 & 382.31 & -0.33 & 26.53 & 21.39 & -0.51 & 5.28 & 0.77 & 0.64 \\
\hline & GARCH $(1,2)$ & 447.18 & 459.83 & 0.47 & 28.78 & 23.25 & -1.23 & 5.77 & 0.98 & 0.54 \\
\hline
\end{tabular}

Note: * indicates the best model and used further for forecasting purpose.
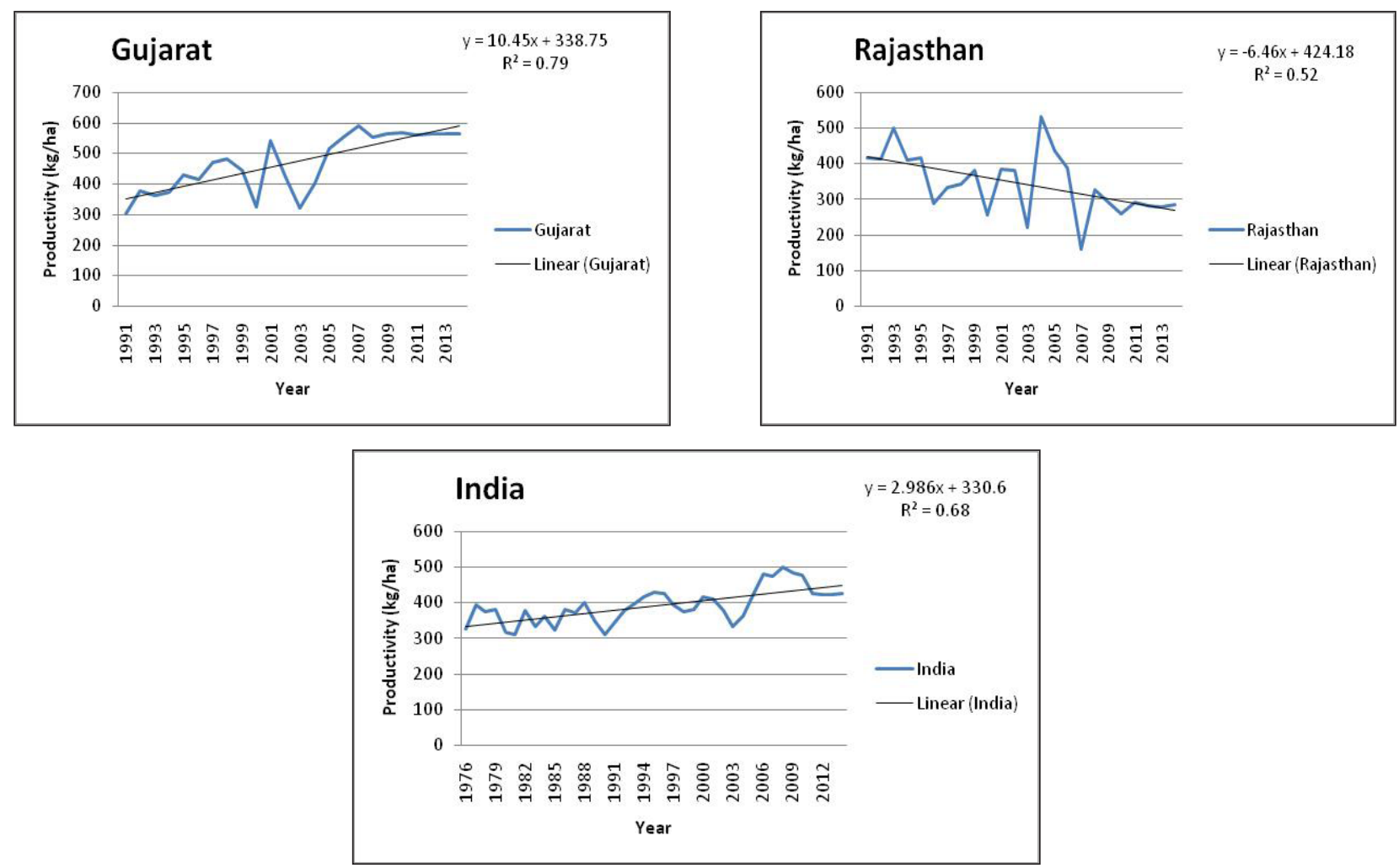

Fig. 1C: Observed and expected trends of productivity under cumin in major states of India 
Table 5: Validation and forecasting of area under cumin in India on the basis of selected best model

\begin{tabular}{|c|c|c|c|c|c|c|c|c|c|c|}
\hline \multirow{2}{*}{ State } & \multirow{2}{*}{ Model } & 2012 & & 2013 & & 2014 & & 2016 & 2018 & 2020 \\
\hline & & Observed & Predicted & Observed & Predicted & Observed & Predicted & Predicted & Predicted & Predicted \\
\hline \multicolumn{11}{|c|}{ Area ('000 ha) } \\
\hline Gujarat & $\operatorname{ARIMA}(1,2,1)$ & 374 & 379 & 374 & 374 & 370 & 377 & 368 & 372 & 381 \\
\hline Rajasthan & $\operatorname{ARIMA}(1,1,2)$ & 368 & 318 & 220 & 252 & 220 & 217 & 223 & 205 & 234 \\
\hline India & $\operatorname{ARIMA}(1,1,2)$ & 843 & 757 & 794 & 742 & 759 & 786 & 808 & 843 & 878 \\
\hline \multicolumn{11}{|c|}{ Production ('000 tonnes) } \\
\hline Gujarat & $\operatorname{ARIMA}(1,1,1)$ & 283 & 230 & 283 & 294 & 280 & 306 & 329 & 352 & 375 \\
\hline Rajasthan & $\operatorname{ARIMA}(1,1,2)$ & 178 & 158 & 111 & 107 & 165 & 132 & 144 & 143 & 143 \\
\hline India & $\operatorname{ARIMA}(1,2,1)$ & 486 & 498 & 486 & 498 & 489 & 498 & 513 & 538 & 562 \\
\hline \multicolumn{11}{|c|}{ Productivity $(\mathrm{Kg} / \mathrm{Ha})$} \\
\hline Gujarat & GARCH (1) & 565 & 561 & 565 & 565 & 564 & 565 & 565 & 565 & 565 \\
\hline Rajasthan & $\operatorname{ARIMA}(0,2,1)$ & 280 & 286 & 276 & 278 & 283 & 279 & 283 & 283 & 283 \\
\hline India & $\operatorname{ARIMA}(2,1,1)$ & 422 & 392 & 421 & 418 & 423 & 418 & 416 & 413 & 414 \\
\hline
\end{tabular}

factors are influencing productivity of cumin; by and large nitrogen is the major factor to significantly effect on the cumin productivity.

\section{Modeling and Forecasting}

From Table 4, shows the comparison between the GARCH and ARIMA model and used for forecasting purpose up to 2020. Best of ARIMA and GARCH models are selected based on the minimum value AIC, BIC, ME, RMSE, MAE, MPE, MAPE and maximum value of $\mathrm{R}^{2}$. The selected models are also validated for accuracy by using last three years data and observed that the actual and predicted values are in range (Table 5). From the table it is clear that $\operatorname{ARIMA}(1,2,1)$ for Gujarat, $\operatorname{ARIMA}(1,1,2)$ for Rajasthan and whole India are found to be best ARIMA model for modeling area of cumin cultivation. Similarly among the various GARCH models, GARCH(1,2) for Rajasthan was best fitted GARCH models, whereas data series of area under cumin in Gujarat and whole India is found not to have GARCH effect. From the Table 4, it is clear that $\operatorname{ARIMA}(1,2,1), \operatorname{ARIMA}(1,1,1)$ and $\operatorname{ARIMA}(1,1,2)$ are found to be best ARIMA models for modeling cumin production in Gujarat, Rajasthan and whole India respectively. In the same way, among the various GARCH models, GARCH(1,2) for Rajasthan was best fitted GARCH model, whereas data series of cumin production in Gujarat and whole India are found not to have GARCH models. For modeling cumin productivity in Rajasthan and whole India
ARIMA models are found to be better than GARCH. Considering Gujarat data series, GARCH(1) model is found to be the best fitted.. Rajasthan shows no improvement, future year value remains same as base year 2014 value and whole India shows declined value for future 2020 as compared to base year 2014.

\section{CONCLUSION}

Thus, from the study of per se performance of area, production and productivity of cumin the following salient features are emerge out. Gujarat is highest contributor of cumin followed by Rajasthan in India. Considering the annual growth rate the state Rajasthan registered highest in case of area and production. Gujarat registered highest annual growth rate in case of productivity. Cumin, ARIMA model fitted well most compare to GARCH model. On the basis of forecasted value, area of cumin, whole India will be reached 878 '000 ha in year 2020. In production Forecasted value shows increased trend in productivity as compared to the base year in the state of Gujarat. The state Gujarat indicates there would be marginal improvement in cumin productivity for 2020. Appropriate policies and high yielding varieties, resistant to adverse environmental condition varieties are required to increase the cumin productivity.

\section{REFERENCES}

Anonymous. 2016. Cumin seasonal synopsis, http://www. commodityindia.com/ last accessed 10/07/2017. 
Anonymous. 2017. Major state wise production of spices in India, http://www.indianspices.com/ last accessed 13/07/2017.

Borthakur, S. and Bhattacharya, B.K. 1998. Trend analysis of area, production and productivity of potato in Assam". Economic Affairs, 43(4): 221-226.

Box, G.E.P. and Jenkins, G.M. 1976. Time series analysis: Forecasting and control. Holden- day, San Fransisco.

Bollerslev, T. 1986. Generalized Autoregressive Conditional Heteroskedasticity. J Econnmet., 31(4): 307-327.
Mishra, P., Padmanaban, K. and Dwivedi Meenakshee 2017. Modelling and Forecasting of Black Pepper Production in India. Indian Journal of Ecology, 44(4): 741-745.

Sahu, P.K. and Mishra, P. 2013. Modelling and forecasting production behaviour and import- export of total spices in two most populous countries of the world. Journal of Agriculture Research, 51(4): 81-97. 
